\title{
Comparison of Two Methods for Implementing Comfort Care Order Sets in the Inpatient Setting: a Cluster Randomized Trial
}

\author{
F. Amos Bailey, MD ${ }^{1,2,3}$, Beverly R. Williams, $P h D^{1,2}$, Patricia S. Goode, MD, MSN ${ }^{1,2}$, \\ Richard E. Kennedy, MD, PhD ${ }^{1,2}$, David T. Redden, PhD ${ }^{1,4}$, Elizabeth Kvale, MD, MSPH ${ }^{1,5}$, \\ Marie Bakitas, DNSc, APRN ${ }^{1,6}$, J. Nicholas Dionne-Odom, $P h D, R N^{6}$, and \\ Kathryn L. Burgio, $P h D^{1,2}$ (D)
}

\begin{abstract}
'Birmingham/Atlanta Geriatric Research, Education, and Clinical Center (GRECC), Birmingham VA Medical Center, Birmingham, AL, USA; ${ }^{2}$ University of Alabama at Birmingham School of Medicine, Birmingham, AL, USA; ${ }^{3}$ University of Colorado at Denver Anschutz Medical Campus, Aurora, CO, USA; ${ }^{4}$ University of Alabama at Birmingham School of Public Health, Birmingham, AL, USA; ${ }^{5}$ University of Texas at Austin School of Medicine, Austin, TX, USA; UUniversity of Alabama at Birmingham School of Nursing, Birmingham, AL, USA.
\end{abstract}

BACKGROUND: There is an ongoing need for interventions to improve quality of end-of-life care for patients in inpatient settings.

OBJECTIVE: To compare two methods for implementing a Comfort Care Education Intervention for Palliative Care Consultation Teams (PCCT) in Veterans Affairs Medical Centers (VAMCs).

DESIGN: Cluster randomized implementation trial conducted March 2015-April 2019. PCCTs were assigned to a traditional implementation approach using a teleconference or to an in-person, train-the-champion workshop to prepare PCCTs to be clinical champions at their home sites.

PARTICIPANTS: One hundred thirty-two providers from PCCTs at 47 VAMCs.

INTERVENTIONS: Both training modalities involved review of educational materials, instruction on using an electronic Comfort Care Order Set, and coaching to deliver the intervention to other providers.

MAIN MEASUREMENTS: Several processes of care were identified a priori as quality endpoints for end-of-life care (last 7 days) and abstracted from medical records of veterans who died within 9 months before or after implementation $(n=6,491)$. The primary endpoint was the presence of an active order for opioid medication at time of death. Secondary endpoints were orders/administration of antipsychotics, benzodiazepines, and scopolamine, do-notresuscitate orders, advance directives, locations of death, palliative care consultations, nasogastric tubes, intravenous lines, physical restraints, pastoral care visits, and family presence at/near time of death. Generalized estimating equations were conducted adjusting for potential covariates.

KEY RESULTS: Eighty-eight providers from 23 VAMCs received teleconference training; 44 providers from 23 VAMCs received in-person workshop training. Analyses found no significant differences between intervention groups in any process-of-care endpoints (primary

Prior Presentations $N / A$

Received June 15, 2020

Accepted December 15, 2020

Published online February 5, 2021 endpoint AOR $(\mathrm{CI})=1.18(0.74,1.89)$. Furthermore, prepost changes were not significant for any endpoints (primary endpoint AOR $(\mathrm{CI})=1.16(0.92,1.46)$. Analyses may have been limited by high baseline values on key endpoints with little room for improvement.

CONCLUSION: Findings suggest the clinical effectiveness of palliative care educational intervention was not dependent on which of the two implementation methods was used.

TRIAL REGISTRATION: ClinicalTrials.gov identifier: NCT02383173

KEY WORDS: end-of-life care; palliative care; Veterans; inpatient; implementation; training/education; educational intervention.

$\mathrm{J}$ Gen Intern Med 36(7):1928-36

DOI: $10.1007 / \mathrm{s} 11606-020-06482-\mathrm{x}$

(C) This is a U.S. government work and not under copyright protection in the U.S.; foreign copyright protection may apply 2021

\section{INTRODUCTION}

Patients near the end of life often are not recognized as imminently dying. ${ }^{1-6}$ Their suffering may not be appreciated or managed properly, and it may be exacerbated by usual medical care involving aggressive, futile, or iatrogenically harmful treatments. ${ }^{7,8}$ To reduce suffering and improve quality of care, it is imperative for clinicians to know how to identify imminently dying patients and implement supportive and comfort care treatment plans. ${ }^{9,10}$

Implementing processes to enhance quality of care at end of life has been recognized as a key priority for decades. National and international task forces have embraced palliative care in response to a call to improve care at the end-of-life, ${ }^{11}$ leading to the development and testing of various upstream and downstream patient and family-focused interventions designed to change care across settings. ${ }^{12-27}$ Yet, implementation and dissemination of evidence-based practices in inpatient settings have shown limited success, ${ }^{14,21,24,25,28,29}$ including comfort care order sets ${ }^{25}$ and interventions to improve end-of-life care in intensive care units. ${ }^{21,28}$ 
In response to a lack of effective implementation strategies for palliative and hospice care at end of life, we developed an education-based comfort care intervention to teach providers in Veterans Affairs Medical Centers (VAMCs) how to identify actively dying patients in inpatient settings and to implement best practices of hospice home care. ${ }^{30}$ The "Best Practices for End-of-Life Care for Our Nation's Veterans" (BEACON I) intervention was evaluated in six VA Medical Centers. ${ }^{30}$ Provider training included a hospice-based Comfort Care Order Set (CCOS) decision support tool embedded in the electronic medical record. This study demonstrated statistically significant changes in several processes of care, including availability of symptom-focused medications, including opioid pain medications $(\mathrm{AOR}(\mathrm{CI})=1.39(1.09,1.76))$, and a reduction in unhelpful or potentially harmful interventions.

Although the effectiveness of the Intervention was demonstrated, it was implemented with intensive involvement of the research team, who traveled to each site and spent 2 weeks providing staff training on all shifts throughout the hospital. Because this approach is not feasible or ideal for large-scale dissemination, it became necessary to identify alternative strategies for broader implementation. A formative evaluation was conducted to understand the processes facilitating adoption of best practices and to inform the design of future dissemination. ${ }^{31}$ Participant accounts detailed how small group instruction and interactive teaching methods facilitated active learning. They also indicated the need for a train-thechampion model, where training could be ongoing at each site, allowing for a more sustained delivery of training.

Hence, the purpose of this study was to evaluate and compare two methods of delivering the BEACON intervention utilizing the established infrastructure of VA Palliative Care Consult Teams (PCCT): a traditional implementation approach using a teleconference and an enhanced implementation approach utilizing in-person, train-the-champion workshops, both to review educational materials and prepare PCCT members to be on-site clinical champions.

\section{METHODS}

\section{Overview}

This study was a cluster randomized implementation trial in which 47 PCCTs were assigned to receive the BEACON Comfort Care Education Intervention via a teleconference or in-person workshop implementation approach. Data on processes of end-of-life care before and after implementation of the intervention were derived from the Computerized Patient Record System (CPRS) files of veterans who died in the VAMC hospitals. The study was conducted March 2015-April 2019. It was approved by the Institutional Review Board for human use. All participants signed informed consent forms.

\section{Participants}

PCCT teams at selected VAMCs were recruited. All VAMCs are mandated to maintain an interdisciplinary PCCT to serve facility-wide needs for palliative care. ${ }^{32,33}$ To avoid ceiling effects and lack of readiness, teams were not recruited if their VAMCs scored in the highest or lowest 10th percentiles on the Performance Reporting and Outcomes Measurement to Improve the Standard of Care at End-of-life (PROMISE) Bereaved Family Survey, a 19-item family satisfaction measure. ${ }^{34,35}$ Additional exclusion criteria were (1) no prescribing provider on the PCCT (enabling use of the CCOS); (2) PROMISE scores not reported; and (3) current use of a comfort care order set.

\section{Randomization}

To avoid baseline differences between groups of sites in quality of end-of-life care, PCCT sites were stratified on two factors: presence vs. absence of an inpatient palliative care unit, and higher vs. lower baseline scores on the PROMISE survey based on median split. Having an inpatient unit may affect the processes by which patients receive care. PROMISE scores should reflect the general quality of care provided. Within these strata, teams were randomized to the teleconference or in-person workshop implementation approach.

\section{Power}

Power calculations were based on primary endpoint data from the BEACON I study, change in proportion of patients with an active opioid order at time of death. Sample sizes of 2400 patients in each group (24 clusters per group with 100 patients per cluster) would achieve $86 \%$ power to detect a difference between group proportions of 0.05 , where the proportion of patients post-intervention with an active opioid order at death in the teleconference group was 0.65 and the proportion in the workshop group was 0.70 . The significance level was 0.05 and an intraclass correlation coefficient was assumed to be 0.005 , as observed in the original trial. Calculations were performed using PASS 11.0.

\section{Comfort Care Education Intervention}

The BEACON Comfort Care Intervention targeted providers and used a multi-modal approach to changing provider practice patterns for end-of-life care. It included didactic information on how to identify and care for patients who are dying in the hospital setting, the CCOS, pocket cards, and other tools and training materials needed to train staff at their own hospital. The materials described a number of comfort care interventions appropriate for patients at the end of life. They were derived from the best practices for care in the last days or hours of life as practiced in the home hospice setting and modified for use in inpatient care settings. ${ }^{36,37}$ Training materials are available at https://www.uab.edu/medicine/palliativecare/ training/resources/beacon. 
The two groups of trainees received the same preimplementation preparation and the same education intervention packet of materials. They differed only on the implementation approach used to deliver the education intervention (Table 1).

Pre-implementation preparation included identifying a lead physician or nurse practitioner champion to spearhead ongoing palliative care education and the CCOS. Each site's PCCT team was provided with the assistance of a computer applications coordinator (CAC) and a clinical provider at the coordinating site, to work remotely with the local PCCT and CAC to construct a Comfort Care Order Set (CCOS) tailored and integrated into the local VAMC's CPRS. These order sets could be customized for individual patients, and all or some of the orders could be selected as appropriate and integrated into existing care plans.

For both groups, a trainer from the coordinating center reviewed the education packet materials and the basic functions of the CCOS with PCCT members who were coached in the use of the materials to train other staff. Trainees also reviewed their role as champions and drivers of culture change. To support the addition of medications or routes of administration to the pharmacy formulary, teams were assisted in working with local administration to change policies and

Table 1 Components of Comfort Care Education Intervention/ Implementation

Pre-implementation preparation

Communicate with administrative leaders

Communicate with Palliative Care Consult Team members

Communicate with Information Resource Management representative

Technical assistance to build Comfort Care Order Set in the

Computerized Patient Record System

Education intervention package materials

Case identification

Comfort care interventions

Comfort Care Order Set

Pocket cards

- When to consider palliative care

- Identifying the actively dying patient

- Comfort care orders

- Equianalgesic opioid conversion card

- Sharing bad news

- Guidelines for death pronouncement

Sample policies and procedures

- Subcutaneous intermittent and continuous infusion

- Nutrition screening and modification for hospice/palliative care

PowerPoint slides for training other providers

Implementation strategy

Activate Comfort Care Order Set

Teleconference

Orientation and review of

education packet materials $(80$ $\min )$

In-person workshop

In-person workshop at BVAMC

(2 days)

Interactive teaching on comfort care interventions

Case-based coaching to build care plans using CCOS

Hands-on experiences with using the CCOS

Teaching to become trainers and change agents (with manual)

Charge to train providers at home facility

Training team available for consultation as needed by PCCT members procedures, particularly those related to morphine concentrate, sublingual administration, and use of subcutaneous lines.

\section{Implementation Strategies}

PCCTs in both arms of the study were exposed to their respective implementation strategy for 4 months. They were charged with training as many appropriate providers as possible at their home facility who may have contact with patients who are imminently dying. During implementation, the training team was available for consultation with teams requesting assistance.

Teleconference. The teleconference arm was designed to align with standard VA training methods. There was no limit to how many PCCT members could participate from each site. In this group, the intervention was delivered in an 80-min teleconference guided by a PowerPoint presentation providing didactic instruction and facilitating group discussion. The standardized curriculum included review of the education packet and teaching to become change agents.

In-Person Train-the-Champion Workshop. Two to three PCCT members from each team traveled to the coordinating center to attend a 2-day, in-person workshop. Ideally, this included a physician and advance practice practitioner with prescribing privileges, so that both would have access to the CCOS and be able to train others. The training team provided a standardized curriculum, including review of the education packet; case-based coaching to build care plans using the CCOS; hands-on computer lab experiences using the CCOS; and coaching to become champions (trainers and change agents). Small group discussions were used to review experiences with the CCOS and compare care plans.

PCCT members reviewed teaching concepts, techniques, and materials for training other providers. During the 4month implementation period, regularly scheduled conference calls were available for the most recently trained workshop participants to discuss the team's local implementation.

\section{Measurement}

Utilizing a chart abstraction tool designed for the study, a physician abstracted data from the electronic medical records on processes of end-of-life care during the last 7 days of life for veterans who had died as inpatients in acute care units. Data for long-term care units were not included. We collected data for all patients who died in the 9 months before and the 9 months after the intervention period at each site.

Several processes of care were identified a priori as primary and secondary endpoints to indicate quality of end-of-life care. The primary endpoint was presence of an active order for opioid medication at the time of death, because of its importance in the management of pain and dyspnea. Secondary 
endpoints were selected processes of care representing the development of a comprehensive care plan for actively dying patients. These included orders for and administration of appropriate medications, including antipsychotic medications for delirium or nausea and vomiting, benzodiazepines for anxiety and treatment or prevention of seizures, and medication to control excessive secretions (death rattle).

In addition, the following quality endpoints were abstracted: indicators of communication regarding goals of care (do-not resuscitate [DNR] order in place at the time of death, advance directive), palliative care consultation, orders for environmental changes to enhance patient safety and comfort (nasogastric tubes, intravenous lines infusing, restraints, and location of death), pastoral care visits, and family presence at or near the time of death. Clinical data included diagnoses (ICD-9 codes), locations of care within the hospital, and length of stay.

Inter-rater reliabilities for the primary outcome measures were established between the chart abstractor and the Director of Palliative Care at the coordinating center as the gold standard, based on review of $5 \%$ of charts. We calculated reliabilities using Gwet's agreement statistic in the R package rel due to the large number of ties, which showed excellent agreement of 0.999 (95\% CI $0.998,0.999)$ across 381 records. ${ }^{38}$

\section{Statistical Analysis}

Processes of care were examined with generalized estimating equations (GEE) to account for clustering of participants, using a compound symmetric correlation structure to model the correlation of participants within sites. ${ }^{39}$ Initial univariate analyses estimated crude associations between processes of care and study phase (pre- or post-intervention), type of intervention (teleconference or workshop), and study phase $\mathrm{X}$ intervention interaction. Multivariate analyses examined the associations of processes of care with study phase and type of intervention. We adjusted the analyses for age, race, terminal condition (cancer/other), length of stay, and study year, because they could conceivably affect outcomes and showed small but statistically significant differences between groups.

Interactions between study phase and type of intervention were not included in multivariate analyses if these were not significant in univariate analyses. Secular trends were evaluated by including an interaction of study year and type of intervention. Sandwich estimators were used with adjustment of the degrees of freedom to account for the small number of clusters. ${ }^{40-43}$ Data were analyzed using SAS version 9.2 (SAS Institute, Cary, NC). Data reporting was guided by the Standards for Reporting Implementation Studies (StaRI). ${ }^{44}$

\section{RESULTS}

Among the 152 VAMCs nationwide, 41 were ineligible based on prior participation in the BEACON I implementation, not reporting PROMISE scores, or having PROMISE scores in the top or bottom $10 \%$, leaving 111 sites eligible for active recruitment (Fig. 1). Eight of the remaining sites could not be contacted, 29 declined to participate, and 27 were ineligible based on current use of a palliative care order set. Forty-seven sites were randomized, 23 to the teleconference group and 24 to the in-person workshop group. One site dropped out prior to training (workshop) and one site dropped out after training (teleconference).

\section{Characteristics of the Providers}

Six waves of training were conducted with 132 providers from PCCTs at 46 VAMCs. Eighty-eight providers from 23 VAMCs received teleconference training, and 44 providers from 23 VAMCs received in-person workshop training (due to the limit on number of travelers). Sixty percent of participants were prescribing providers (42\% physicians, $17 \%$ nurse practitioners), $40 \%$ were non-prescribing providers ( $17 \% \mathrm{RNs}, 8 \%$ pharmacists, $7 \%$ mental health providers), and $8 \%$ were from other services.

\section{Characteristics of Deceased Veterans}

The medical records of 6,491 veterans who died in the VAMCs during the study period were abstracted. Table 2 presents the characteristics of the sample by intervention group (3,078 for teleconference, 3,413 for workshop). The overall sample was predominantly male $(97.5 \%)$ with a mean age of 75.0 years and slightly over $20 \%$ were African American. The sample was balanced across sites by cause of death.

\section{Changes in Processes of Care}

Changes in process-of-care endpoints are presented by group in Table 3. It is noteworthy that the use of the process-of-care interventions was already at or near optimal levels before the intervention was implemented. For example, before the implementation, $89.8 \%$ of deceased patients had an active order for an opioid (88.4\% teleconference, 91.0 workshop), and $90.3 \%$ had a DNR order (88.8\% teleconference, 91.7 workshop).

GEE analyses of between group differences found no significant differences between the teleconference and workshop groups on the primary endpoint or any of the secondary endpoints (primary endpoint AOR $(\mathrm{CI})=1.18(0.74,1.89)$ (Table 4). Furthermore, the pre-post changes were not significant for any endpoint (primary outcome AOR $(\mathrm{CI})=1.16(0.92$, 1.46).

\section{DISCUSSION}

The results of this trial indicate that using a 2-day in-person workshop to deliver an education intervention enabling providers to optimally implement a comfort care order set does not produce better process-of-care outcomes compared to using a traditional teleconference. Furthermore, neither implementation strategy demonstrated significant changes in the use 


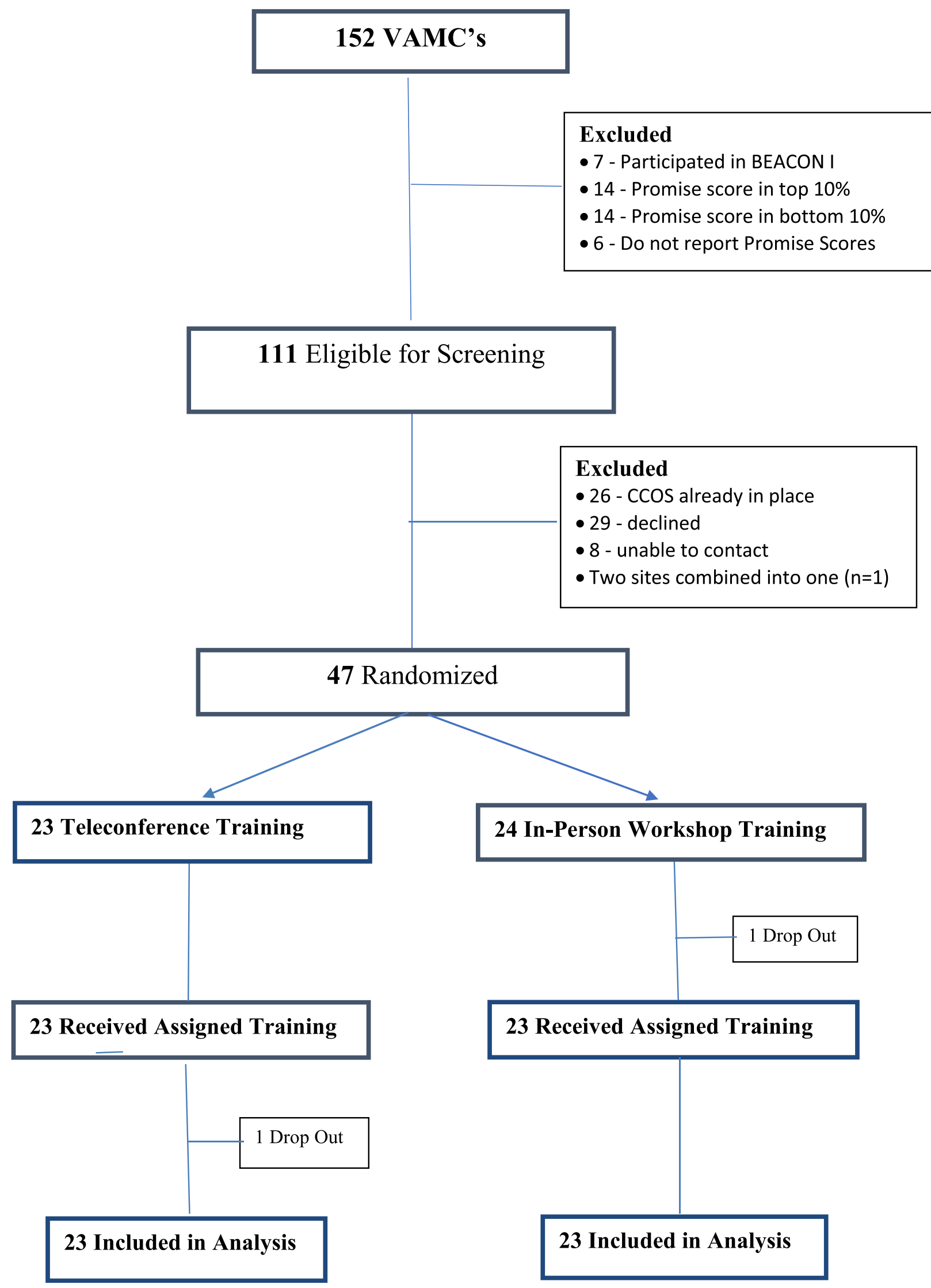

Figure 1 CONSORT diagram. 
Table 2 Characteristics of Deceased Veterans

\begin{tabular}{|c|c|c|c|c|}
\hline & $\begin{array}{l}\text { Teleconference } \\
\text { Pre }(N=1559)\end{array}$ & $\begin{array}{l}\text { Workshop } \\
\text { Pre }(N=1726)\end{array}$ & $\begin{array}{l}\text { Teleconference } \\
\text { Post }(N=1519)\end{array}$ & $\begin{array}{l}\text { Workshop } \\
\text { Post }(N=1687)\end{array}$ \\
\hline Age, years (Mean, SD) & $74.2(11.5)$ & $75.6(11.4)$ & $74.32(11.8)$ & $75.6(11.3)$ \\
\hline \multicolumn{5}{|l|}{ Race, $n(\%)$} \\
\hline White & $1069(68.6)$ & $1225(71.0)$ & $1027(67.6)$ & $1190(70.5)$ \\
\hline Black & $333(21.4)$ & $387(22.4)$ & $326(21.5)$ & $364(21.6)$ \\
\hline Native American & $6(0.4)$ & $10(0.6)$ & $5(0.3)$ & $12(0.7)$ \\
\hline Asian & $6(0.4)$ & $5(0.3)$ & $9(0.6)$ & $9(0.5)$ \\
\hline Pacific Islander & $15(1.0)$ & $6(0.4)$ & $18(1.2)$ & $10(0.6)$ \\
\hline Other & $130(8.3)$ & $95(5.5)$ & $134(8.8)$ & $102(6.1)$ \\
\hline Ethnicity, Hispanic, $n(\%)$ & $104(6.7)$ & $72(4.2)$ & $83(5.5)$ & $68(4.0)$ \\
\hline Sex, male, $n(\%)$ & $1531(98.3)$ & $1676(97.1)$ & $1470(96.8)$ & $1649(97.8)$ \\
\hline \multicolumn{5}{|l|}{ Terminal condition, $n(\%)$} \\
\hline Cancer & $665(42.7)$ & $800(46.4)$ & $585(38.5)$ & $759(44.9)$ \\
\hline Dementia & $113(7.3)$ & $150(8.7)$ & $134(8.8)$ & $109(6.5)$ \\
\hline Lung disease & $136(8.7)$ & $156(9.0)$ & $117(7.7)$ & $146(8.7)$ \\
\hline Heart disease & $288(18.5)$ & $287(16.6)$ & $297(19.6)$ & $311(18.4)$ \\
\hline Kidney disease & $95(6.1)$ & $106(6.1)$ & $106(7.0)$ & $101(6.0)$ \\
\hline Liver disease & $111(7.1)$ & $80(4.6)$ & $83(5.5)$ & $62(3.7)$ \\
\hline Stroke & $109(7.0)$ & $92(5.3)$ & $115(7.6)$ & $95(5.6)$ \\
\hline HIV & $19(1.2)$ & $8(0.5)$ & $11(0.7)$ & $17(1.0)$ \\
\hline Acute illness & $494(31.7)$ & $513(29.7)$ & $557(36.7)$ & $559(33.1)$ \\
\hline None/unexpected & $152(9.8)$ & $148(8.6)$ & $180(11.9)$ & $180(10.7)$ \\
\hline Length of stay, mean (SD) & $2.26(1.3)$ & $2.42(1.4)$ & $2.21(1.3)$ & $2.29(1.3)$ \\
\hline \multicolumn{5}{|l|}{ Study year, $n(\%)$} \\
\hline 2015 & $502(32.2)$ & $532(30.8)$ & $0(0.0)$ & $0(0.0)$ \\
\hline 2016 & $499(32.0)$ & $667(38.6)$ & $468(30.8)$ & $483(28.6)$ \\
\hline 2017 & $558(35.8)$ & $527(30.5)$ & $516(34.0)$ & $691(41.0)$ \\
\hline 2018 & $0(0.0)$ & $0(0.0)$ & $535(35.5)$ & $513(30.4)$ \\
\hline
\end{tabular}

of the comfort care interventions in the 9 months following the intervention period.

One might expect that the in-person workshop would yield better process-of-care outcomes than teleconference due to greater exposure to the training ( 2 days vs. $80 \mathrm{~min}$ ), the interactive face-to-face teaching, sharing between teams, hands-on computer training on the CCOS, and the ability to focus on the training by being away from day-to-day duties. While we thought these elements might make a difference, they do not appear to be essential components for enhancing PCCT ability to implement CCOS interventions.

The lack of significant group differences may be explained by the fact that the trainees were all palliative care practitioners working in a healthcare system with a two-decade-long mandate to improve end-of-life care. ${ }^{45,46}$ Furthermore, the basic curriculum and materials, as well as the CCOS, were the same in the two groups. Perhaps the presence of the CCOS itself was the more salient component in shaping processes of care in the inpatient setting.

Given the significant improvements in process-of-care outcomes observed in the BEACON I trial, the lack of pre-post change in BEACON II was unexpected. It may be that the analyses were limited by high baseline values on some key endpoints leaving little room for improvement. These levels may represent a ceiling effect, given that $9.1 \%$ of deaths were unexpected, and it can be assumed that the interventions

Table 3 Process of End-of-Life Care Endpoints in Teleconference versus Workshop Groups (No. (\%))

\begin{tabular}{|c|c|c|c|c|}
\hline & $\begin{array}{l}\text { Teleconference } \\
\text { Pre }(N=1559)\end{array}$ & $\begin{array}{l}\text { Workshop } \\
\text { Pre }(N=1726)\end{array}$ & $\begin{array}{l}\text { Teleconference } \\
\text { Post }(N=1519)\end{array}$ & $\begin{array}{l}\text { Workshop } \\
\text { Post }(N=1687)\end{array}$ \\
\hline Opioid order at time of death & $1378(88.4)$ & $1571(91.0)$ & $1330(87.6)$ & $1543(91.5)$ \\
\hline Administration of opioid ( $\%$ of those with an order) & $1322(95.8)$ & $1526(96.8)$ & $1275(95.5)$ & $1484(96.0)$ \\
\hline Antipsychotic order at time of death & $630(40.4)$ & $768(44.5)$ & $635(41.8)$ & $720(42.7)$ \\
\hline Administration of antipsychotic (\% of those with an order) & $454(72.8)$ & $538(70.7)$ & $420(67.8)$ & $483(68.3)$ \\
\hline Benzodiazepine order at time of death & $1030(66.1)$ & $1126(65.2)$ & $1025(67.5)$ & $1117(66.2)$ \\
\hline Administration of benzodiazepine ( $\%$ of those with an order) & $861(83.6)$ & $960(84.5)$ & $831(80.5)$ & $966(85.8)$ \\
\hline Death rattle medication order & $821(52.7)$ & $954(55.3)$ & $881(58.0)$ & $1004(59.5)$ \\
\hline DNR in place at time of death & $1384(88.8)$ & $1583(91.7)$ & $1336(88.0)$ & $1504(89.2)$ \\
\hline DNR ordered $>24 \mathrm{~h}$ before death & $1272(81.6)$ & $1427(82.7)$ & $1204(79.3)$ & $1383(82.0)$ \\
\hline Advance directive & $1007(64.6)$ & $1144(66.3)$ & $913(60.1)$ & $1115(66.1)$ \\
\hline Palliative care consult & $1216(78.0)$ & $1473(85.3)$ & $1208(79.5)$ & $1426(84.5)$ \\
\hline Nasogastric tube & $161(10.3)$ & $157(9.1)$ & $161(10.6)$ & $141(8.4)$ \\
\hline Intravenous fluids & $184(11.8)$ & $170(9.9)$ & $141(9.3)$ & $184(10.9)$ \\
\hline Restraints & $78(5.0)$ & $90(5.2)$ & $86(5.7)$ & $73(4.3)$ \\
\hline Death in ICU & $455(29.2)$ & $395(22.9)$ & $436(28.7)$ & $408(24.2)$ \\
\hline Death on palliative care unit & $776(49.8)$ & $1013(58.7)$ & $781(51.4)$ & $969(57.4)$ \\
\hline Pastoral consult & $1126(72.2)$ & $1299(75.3)$ & $1060(69.8)$ & $1271(75.3)$ \\
\hline Family present at time of death & $755(48.4)$ & $866(50.2)$ & $737(48.5)$ & $844(50.0)$ \\
\hline
\end{tabular}


Table 4 Multivariable Analyses

\begin{tabular}{|c|c|c|c|c|c|}
\hline & \multicolumn{3}{|c|}{ Unadjusted* (OR, CI) $^{*}$} & \multicolumn{2}{|c|}{ Adjusted $^{\dagger}(\mathrm{OR}, \mathrm{CI})$} \\
\hline & $\begin{array}{l}\text { Teleconference/ } \\
\text { workshop }\end{array}$ & Pre/post & Interaction & $\begin{array}{l}\text { Teleconference/ } \\
\text { workshop }\end{array}$ & Pre/post \\
\hline Opioid order at time of death & $1.40(0.83,2.38)$ & $\begin{array}{l}0.97(0.83 \\
1.12)\end{array}$ & $\begin{array}{l}0.92(0.42, \\
1.97)\end{array}$ & $1.18(0.74,1.89)$ & $\begin{array}{l}1.16(0.92, \\
1.46)\end{array}$ \\
\hline Administration of opioid & $1.25(0.85,1.85)$ & $\begin{array}{l}0.82(0.55 \\
1.21)\end{array}$ & $\begin{array}{l}1.30(0.60 \\
2.79)\end{array}$ & $1.29(0.87,1.91)$ & $\begin{array}{l}0.79(0.48 \\
1.29)\end{array}$ \\
\hline $\begin{array}{l}\text { Antipsychotic order at time of } \\
\text { death }\end{array}$ & $1.24(0.65,2.36)$ & $\begin{array}{l}0.97(0.84, \\
1.11)\end{array}$ & $\begin{array}{l}1.09(0.44 \\
2.71)\end{array}$ & $1.05(0.52,2.14)$ & $\begin{array}{l}0.99(0.78 \\
1.25)\end{array}$ \\
\hline Administration of antipsychotic & $0.92(0.71,1.19)$ & $\begin{array}{l}0.85(0.65 \\
1.10)\end{array}$ & $\begin{array}{l}0.99(0.59 \\
1.65)\end{array}$ & $0.90(0.69,1.17)$ & $\begin{array}{l}0.85(0.63 \\
1.15)\end{array}$ \\
\hline $\begin{array}{l}\text { Benzodiazepine order at time of } \\
\text { death }\end{array}$ & $0.93(0.54,1.62)$ & $\begin{array}{l}1.02(0.91, \\
1.15)\end{array}$ & $\begin{array}{l}1.17(0.54 \\
2.55)\end{array}$ & $0.95(0.55,1.65)$ & $\begin{array}{l}1.00(0.85 \\
1.19)\end{array}$ \\
\hline Administration of benzodiazepine & $1.26(0.94,1.70)$ & $\begin{array}{l}0.88(0.65 \\
1.19)\end{array}$ & $\begin{array}{l}0.79(0.44 \\
1.41)\end{array}$ & $1.23(0.90,1.69)$ & $\begin{array}{l}0.83(0.56 \\
1.23)\end{array}$ \\
\hline Death rattle medication order & $1.11(0.66,1.88)$ & $\begin{array}{l}1.19(1.03, \\
1.38)\end{array}$ & $\begin{array}{l}1.09(0.53 \\
2.27)\end{array}$ & $1.26(0.74,2.13)$ & $\begin{array}{l}1.24(0.99, \\
1.56)\end{array}$ \\
\hline DNR in place at time of death & $1.21(0.76,1.93)$ & $\begin{array}{l}0.81(0.66 \\
0.99)\end{array}$ & $\begin{array}{l}1.30(0.63 \\
2.68)\end{array}$ & $1.09(0.72,1.66)$ & $\begin{array}{l}1.06(0.78 \\
1.43)\end{array}$ \\
\hline DNR ordered $>24 \mathrm{~h}$ before death & $0.89(0.661 .30)$ & $\begin{array}{l}1.12(0.97, \\
1.29)\end{array}$ & $\begin{array}{l}1.05(0.61 \\
1.82)\end{array}$ & $0.99(0.79,1.24)$ & $\begin{array}{l}0.97(0.77 \\
1.21)\end{array}$ \\
\hline Advance directive & $1.26(0.86,1.85)$ & $\begin{array}{l}0.90(0.81, \\
1.01)\end{array}$ & $\begin{array}{l}0.92(0.53, \\
1.62)\end{array}$ & $1.23(0.86,1.75)$ & $\begin{array}{l}0.94(0.77, \\
1.15)\end{array}$ \\
\hline Palliative care consult & $1.56(0.93,2.61)$ & $\begin{array}{l}0.98(0.84, \\
1.14)\end{array}$ & $\begin{array}{l}1.49(0.70 \\
3.16)\end{array}$ & $1.31(0.84,2.04)$ & $\begin{array}{l}1.26(0.96 \\
1.66)\end{array}$ \\
\hline Nasogastric tube & $0.84(0.57,1.25)$ & $\begin{array}{l}0.92(0.62 \\
1.37)\end{array}$ & $\begin{array}{l}1.08(0.50 \\
2.35)\end{array}$ & $0.93(0.68,1.27)$ & $\begin{array}{l}0.70(0.46 \\
1.07)\end{array}$ \\
\hline IV fluids & $0.95(0.55,1.64)$ & $\begin{array}{l}0.92(0.75 \\
1.14)\end{array}$ & $\begin{array}{l}0.69(0.32 \\
1.48)\end{array}$ & $0.87(0.52,1.43)$ & $\begin{array}{l}1.05(0.75 \\
1.47)\end{array}$ \\
\hline Restraints & $1.00(0.53,1.88)$ & $\begin{array}{l}1.00(0.77, \\
1.29)\end{array}$ & $\begin{array}{l}1.26(0.50 \\
3.14)\end{array}$ & $1.07(0.63,1.83)$ & $\begin{array}{l}0.94(0.59 \\
1.49)\end{array}$ \\
\hline Death in ICU & $0.74(0.49,1.12)$ & $\begin{array}{l}1.04(0.69, \\
1.57)\end{array}$ & $\begin{array}{l}0.87(0.39 \\
1.98)\end{array}$ & $0.92(0.62,1.36)$ & $\begin{array}{l}0.88(0.55 \\
1.40)\end{array}$ \\
\hline Death on palliative care unit & $1.64(0.94,2.87)$ & $\begin{array}{l}0.94(0.54, \\
1.64)\end{array}$ & $\begin{array}{l}1.08(0.36 \\
3.26)\end{array}$ & $1.07(0.60,1.89)$ & $1.07(0.56,2.0)$ \\
\hline Pastoral consult & $1.16(0.73,1.85)$ & $\begin{array}{l}0.94(0.83, \\
1.06)\end{array}$ & $\begin{array}{l}0.85(0.44 \\
1.63)\end{array}$ & $1.21(0.77,1.90)$ & $\begin{array}{l}1.16(0.96, \\
1.40)\end{array}$ \\
\hline Family present at time of death & $0.99(0.76,1.28)$ & $\begin{array}{l}1.00(0.91, \\
1.09)\end{array}$ & $\begin{array}{l}1.00(0.68 \\
1.46)\end{array}$ & $1.02(0.81,1.29)$ & $\begin{array}{l}0.93(0.79 \\
1.08)\end{array}$ \\
\hline
\end{tabular}

*Teleconference and pre-intervention phase are the reference groups

†Adjusted for age, race, cancer, length of stay, and study year

would not be appropriate in all cases. Furthermore, we may have set our PROMISE score threshold for avoiding ceiling effects too high. We did not foresee the high baseline values on some key endpoints, which were later identified in baseline CPRS chart abstraction.

In addition, the baseline levels of process-of-care endpoints were greater than post-intervention levels observed in BEACON I. These enhanced levels may be attributed to secular trends, possibly including dissemination of BEACON I in the VA Health Care System and other major VA initiatives, as well as continued efforts outside VA. ${ }^{45}$ The quality of palliative and end-of-life care has long been a priority for the VA Healthcare System. ${ }^{32,33}$ The VA was an early adopter of robust palliative care services distributed widely throughout the system which supports the effectiveness of palliative care interventions such as Palliative Care Consults for patientcentered outcomes and family satisfaction. ${ }^{46-48}$ Over decades, the VHA system, through a broad range of palliative care clinical and programmatic initiatives, has demonstrably increased access, use, and quality of palliative care services. ${ }^{49-52}$
One of the limitations of the study is its reliance on patient chart abstraction for measuring processes of care. One might question the selection of the process-of-care variables evaluated or the validity of the chart abstraction method of data collection. We do not believe these are salient issues, because the variables we examined were the same as in BEACON I, where improvements were demonstrated. Furthermore, interrater reliability was high and was assessed in the same way using the ratings by the lead investigator as a gold standard. Finally, changes in practice patterns can take time, especially in large organizations, and may not be reflected in the relatively short 9-month timeframe of the study. Finally, the study was conducted entirely within the VA which has a unique history of palliative care initiatives. Therefore, results could be different when implemented in other healthcare systems. Because changes in practice patterns can be challenging and slow, especially in large organizations, future implementation trials might consider other approaches to behavior change or outcomes at other points in the pathway from training to patient outcomes. 
In conclusion, although an in-person workshop was the training modality preferred by providers from both groups in our analyses of qualitative interviews, ${ }^{53}$ the teleconference is perhaps more economical and resource efficient. These findings can inform considerations of the optimal approaches to palliative care education and training and optimize further nationwide dissemination of best practices for end-of-life care in both VA and non-VA settings.

Acknowledgments: The authors thank the following individuals for their contributions to this work: Keith Swetz, MD, for supporting the inperson workshops, Charles W. Callans, MHA, and Galen Hale, MA, for project coordination; Patricia Maya, MD, for chart abstraction.

Corresponding Author: F. Amos Bailey, MD; University of Colorado at Denver Anschutz Medical Campus, Aurora, CO, USA (e-mail: Amos. bailey@cuanschutz.edu).

Funding This research was supported by a Merit Review grant from the Department of Veterans Affairs, Veterans Health Administration, Office of Research and Development, Health Services Research and Development Service "Evaluation of Methods for Implementation of a Comfort Care Order Set: Best Practices for End-of-Life Care for Our Nation's Veterans (BEACON II)." IIR 12-071. PI: KL Burgio, Co-PI: FA Bailey. The sponsor had no role in the study design; in the collection, analysis, and interpretation of the data; in the writing of the report; and in the decision to submit the paper for publication.

\section{Compliance with Ethical Standards:}

Conflict of Interest: The authors report no conflicts of interest.

Disclaimer: The contents do not represent the views of the US Department of Veterans Affairs or the United States Government.

\section{REFERENCES}

1. Billings JA, Gardner M, Putman AT. A one-day, hospital-wide survey of dying inpatients. J Palliat Med. 2002; 5:363-374.

2. Lynn J, Teno JM, Harrell FE. Accurate prognostication of death: opportunities for clinicians. West J Med. 1995; 163:250-257.

3. Christakis N, Lamont EB. Extent and determinants of errors in doctors prognoses in terminally ill patients: prospective cohort study. BMJ. 2000; 329:469-473.

4. Abarshi EA, Echteld MA, Van den Block L, et al. Recognising patients who will die in the near future: a nationwide study via the Dutch Sentinel Network of GPs. Br J Gen Pract. 2011;61:e371.

5. Hwang IC, Ahn HY, Park SM, Shim JY, Kim KK. Clinical changes in terminally ill cancer patients and death within $48 \mathrm{~h}$ : when should we refer patients to a separate room? Support Care Cancer. 2013;21:835840.

6. Selby D, Chakraborty A, Lilien T, et al. Clinician accuracy when estimating survival duration: the role of the patient's performance status and time-based prognostic categories. J Pain Symptom Manage. 2011;42:578-588.

7. Singer PA, Martin DK, Kelner M. Quality end-of-life care patients' perspectives. JAMA. 1999; 281:163-168.

8. Bylicki O, Didier M, Riviere F, Margery J, Grassin F, Chuaid C. Lung cancer and end-of-life care: a systematic review and thematic synthesis of aggressive inpatient care. BMJ Support Palliat Care. 2019; 9:413-424.

9. Ellershaw J, Ward C. Care of the dying patient: the last hours or days of life. BM 2003; 326: 30-34.

10. Hanson LC, Usher B, Spragens L, Bernard S. Clinical and economic impact of palliative care consultation. J Pain Symptom Manage. 2008; 35:340-346.

11. Shaulov A, Baddarni $\mathbf{K}$, Cherny $\mathbf{N}$, et al. "Death is inevitable - a bad death is not" report from an international workshop. Isr J Health Policy Res. 2019; 8:79.
12. Singer AE, Goebel JR, Kim YS, Dy SM, Ahluwalia SC, Clifford M, Dzeng E, O'Hanlon CE, Motala A, Walling AM, Goldberg J, Meeker D, Ochotorena C, Shanman R, Cui M, Lorenz KA. Populations and Interventions for Palliative and End-of-Life Care: A Systematic Review. J Palliat Med. 2016; 19(9): 995-1008.

13. Dixon J, Matosevic T, Knapp M. The economic evidence for advance care planning: Systematic review of evidence. Palliat Med. 2015; 29:86984.

14. The Support Principal Investigators. A controlled trial to improve care for seriously ill hospital patients: The Study to understand prognoses and preferences for outcomes and risks of treatments (SUPPORT). JAMA. 1995; 274: 1591-1598.

15. Dixon J, Karagiannidou M, Knapp M. The effectiveness of advance care planning in improving end-of-life outcomes for people with dementia and their carers: A Systematic Review and Critical Discussion. J Pain Symptom Manage. 2018; 55:132-150.e1

16. Temel JS, Greer JA, Muzikansky A, et al. Early palliative care for patients with metastatic non-small-cell lung cancer. N Engl J Med. 2010; 363:733-42.

17. LeBlanc TW, Roeland EJ, El-Jawahri A. Early Palliative Care for Patients with Hematologic Malignancies: Is It Really so Difficult to Achieve? Curr Hematol Malig Rep. 2017;12:300-308.

18. Tassinari D, Drudi F, Monterubbianesi MC, et al. Early palliative care in advanced oncologic and non-oncologic chronic diseases: a systematic review of literature. Rev Recent Clin Trials. 2016; 11:63-71.

19. Romano AM, Gade KE, Nielsen G, et al. Early palliative care reduces end-of-life intensive care unit (ICU) use but not ICU course in patients with advanced cancer. Oncologist. 2017; 22:318-323.

20. Sullivan DR, Chan B, Lapidus JA, et al. Association of early palliative care use with survival and place of death among patients with advanced lung cancer receiving care in the Veterans Health Administration. JAMA Oncol. 2019;12:1702-1709.

21. Metaxa V, Anagnostou D, Vlachos S, et al. Palliative care interventions in intensive care unit patients - a systematic review protocol. Syst Rev. 2019; 8:148.

22. Curtis JR, Treece PD, Nielsen EL, et al. Randomized Trial of Communication Facilitators to Reduce Family Distress and Intensity of End-ofLife Care. Am J Respir Crit Care Med. 2016; 193:154-62.

23. Carson SS, Cox CE, Wallenstein S, et al. Effect of Palliative Care-Led Meetings for Families of Patients With Chronic Critical Illness: A Randomized Clinical Trial. JAMA. 2016;316:51-62.

24. Van den Block L, Honinx E, Pivodic L, et al. PACE trial group. Evaluation of a Palliative Care Program for Nursing Homes in 7 Countries: The PACE Cluster-Randomized Clinical Trial. JAMA Intern Med. 2019; 11:1-10.

25. Lau C, Silos K, Nowell A, Lau F, Moore J, Wynnychuk L. Comfort Measures Order Set at a Tertiary Care Academic Hospital: Is There a Comparable Difference in End-of-Life Care Between Patients Dying in Acute Care When CMOS Is Utilized? Am J Hospice Palliat Med. 2018; 35(4): 652-663.

26. Friedrichsen $\mathbf{M}$, Hajradinovic $\mathbf{Y}$, Jakobsson M, Milberg P, Milberg A. Palliative care consultation team on acute words-an intervention study with pre-post comparisons Support Care Cancer. 2017; 25:371-380.

27. Gruhler H, Krutka A, Luetke-Stahlman H, Gardner E. Determining palliative care penetration rates in the acute care setting. $J$ Pain Symptom Manage. 2018; 55(2): 226-235.

28. Horton JR, Morrison RS, Capezuti E. Impact of inpatient palliative care on treatment intensity for patients with serious illness. J Palliat Med. 2016; 19 (9):936-942.

29. Stubbs J, Assareh H, Achat H, Jalaludin B. Inpatient palliative care of people dying in New South Wales hospitals or soon after discharge. Intern Med J. 2019; 49:232-239.

30. Bailey FA, Williams BR, Woodby LL, et al. Intervention to improve care at life's end in inpatient settings: the BEACON Trial. J Gen Intern Med. 2014; 29:836-43

31. Williams BR, Woodby LL, Bailey FA, Burgio KL. Formative evaluation of a multi-component, education-based intervention to improve processes of end-of-life care. Gerontol Geriatr Ed. 2014; 35:4-22.

32. Department of Veterans Affairs Veterans Health Administration Washington, DC. VHA Directive 1139-Palliative Care Consult Teams (PCCT) and VISN Leads, June 14, 2014. https://www.va.gov/VHA/Publications, accessed 6-15-2020.

33. Edes T, Shreve S, Casarett $\mathbf{D}$. Increasing access and quality in the Department of Veterans Affairs care at the end of life: a lesson in change. J Am Geriatr Soc. 2007; 55: 1645-9. 
34. US Department of Veterans Affairs PROMISE Center. Performance Reporting and Outcomes Measurement to Improve the Standard of Care at End-of-Life (PROMISE) Center. http://www.cherp.research.va.gov/ PROMISE.asp. Accessed March 3, 2020.

35. Casarett D, Pickard A, Amos Bailey FA, et al. A Nationwide VA Palliative Care Quality Measure: The Family Assessment of Treatment at the End of Life. J Palliat Med. 2008; 11(1):68-75.

36. Emanuel LL, von Gunten CF, Ferris FD and Hauser, JM. eds. Module 12: Last hours of life. The Education in Palliative and End-of-Life Care (EPEC) Curriculum. Chicago, IL: The EPEC Program, Robert Wood Johnson Foundation, orig. 1999; $3^{\text {rd }}$ edition, 2015.

37. Robinson K, Sutton S, von Gunten CF, et al. Assessment of the Education for Physicians on End-of-Life Care (EPEC) Project. J Palliat Med. 2004;7:637-45.

38. Gwet KL. Computing inter-rater reliability and its variance in the presence of high agreement. Br J Math Stat Psychol. 2008;61(Pt 1):29-48.

39. Diggle PJ, Heagerty, KY, Liang, and Zeger SL. Analysis of longitudina data, volume 25 of Oxford Statistical Science Series. Oxford University Press, Oxford, second edition, 2013.

40. Fay MP, Graubard BI. Small-sample adjustments for Wald-type tests using sandwich estimators. Biometrics. 2001;57:1198-206.

41. Mancl LA, DeRouen TA. A covariance estimator for GEE with improved small-sample properties. Biometrics. 2001; 57:126-34.

42. Pan W, Wall MM. Small-sample adjustments in using the sandwich variance estimator in generalized estimating equations. Stat Med. 2002; 21:1429-41.

43. Kauermann G, Carroll RJ. A note on the efficiency of sandwich covariance estimation. J Am Stat Assoc. 2001; 96:1387-96.

44. Pinnock H, Barwick M, Carpenter C, Eldridge S, et al. for the StaRI Group. Standards for Reporting Implementation Studies (StaRI). BMJ 2017;356:i6795.

45. Schoenherr LA, Bischoff KE, Marks AK, O'Riordan DL, Pantilat SZ. Trends in Hospital-Based Specialty Palliative Care in the United States from 2013 to 2017. JAMA Network Open. 2019;2(12):e1917043.

46. Carpenter JG, McDarby M, Smith D, Johnson M, Thorpe J, Ersek M Associations between Timing of Palliative Care Consults and Family
Evaluation of Care for Veterans Who Die in a Hospice/Palliative Care Unit. J Palliat Med. 2017; 20:745-751.

47. Casarett D, Pickard A, Bailey FA, et al. Do palliative consultations improve patient outcomes? J Am Geriatr Soc. 2008; 56:593-9.

48. Rolnick, JA, Ersek M, Wachterman MW, Halpern SD. The Quality of End-of-Life Care Among Intensive Care Unit Versus Ward Decedents. Am J Resp Crit Care Med. 2020; 201:832-839.

49. Miller SC, Intrator O, Scott W, Shreve ST, Phibbs CS, Kinosian B, Allman RM, Edes TE. Increasing Veterans' Hospice Use: The Veterans Health Administration's Focus on Improving End-Of-Life Care. Health Affairs 2017; 36(7): 1274-1282.

50. Gidwani-Marszowski R, Needleman J, Mor V, Faricy-Anderson $\mathbf{K}$, Boothroyd DB, Hsin G, Wagner TH, Lorenz KA, Patel MI, Joyce VR, Samantha S, Murrell SS, Ramchandran K, Asch SM. Quality Of EndOf-Life Care Is Higher In The VA Compared to Care Paid For By Traditional Medicare. Health Affairs. 2018; 37(1): 95-103.

51. Mor V, Wagner TH, Levy C, Ersek M, Miller SC, Gidwani-Marszowski R, Joyce N, Faricy-Anderson K, Corneau EA, Lorenz K, Kinosian B, Scott Shreve S. Association of Expanded VA Hospice Care with Aggressive Care and Cost for Veterans with Advanced Lung Cancer. JAMA Oncol. 2019;5(6):810-816.

52. Presley CJ, Han L, O'Leary JR, Zhu W, Corneau E, Chao H, Shamas T, Rose M, Lorenz K, Levy CR, Mor V, Gross CP. Concurrent Hospice Care and Cancer-Directed Treatment for Advanced Lung Cancer and Receipt of Aggressive Care at the End of Life in the Veteran's Health Administration. J Palliat Med. March 2020 (Online ahead of print).

53. Williams BR, Bailey FA, Goode PS, et al. "Online Training is Great but Human Interaction is Better:" Training Preferences of VA Interdisciplinary Palliative Care Consult Teams. Am J Hospice Palliat Med, Epub: 2020 Mar 3.

Publisher's Note Springer Nature remains neutral with regard to jurisdictional claims in published maps and institutional affiliations. 